\title{
AKULTURASI ISLAM DALAM BUDAYA LOKAL
}

\author{
Limyah Al-Amri \\ IAIN Sultan Amai Gorontalo \\ Muhammad Haramain \\ STAIN Parepare
}

\begin{abstract}
The subject matter raised in this paper is how acculturation of Islam and local culture in Indonesia. Using historical text studies. In this paper suggests the success of Islam that came from Arabs managed to dialogue and accepted in the local cultural landscape that has long been rooted in the archipelago. The findings are that Islam is able to understand the existing local cultural setting and internalize the cultural setting so that its existence can be accepted by the community. This success is inseparable from the cultural approach adopted by Islamic preachers of the XIII century who acculturate Islamic and local culture so that it becomes an inseparable unity.
\end{abstract}

Keywords: Islam, Local Culture, Acculturation.

\begin{abstract}
Abstrak
Pokok permasalahan yang diangkat dalam tulisan ini adalah bagaimana akulturasi Islam dan budaya lokal di Indonesia. Dengan menggunakan studi teks sejarah. Dalam tulisan ini mengemukakan keberhasilan Islam yang datang dari Arab berhasil berdialog dan diterima dalam lanskap budaya lokal yang telah lama mengakar di Nusantara. Hasil temuannya adalah Islam berhasil memahami setting budaya lokal yang ada dan melakukan internalisasi dalam setting budaya tersebut sehingga eksistensinya dapat diterima oleh masyarakat. Keberhasilan ini tidak terlepas dari pendekatan budaya yang dilakukan oleh pendakwah Islam abad XIII yang melakukan akulturasi budaya Islam dan lokal sehingga menjadi satu kesatuan yang tak terpisahkan.
\end{abstract}

Kata Kunci: Islam, Budaya Lokal, Akulturasi. 


\section{PENDAHULUAN}

Jauh sebelum Islam datang ke Indonesia, di Indonesia telah berkembang agama Hindu, Budha dan agama-agama primitif animistis lainnya, serta tradisi sosial kemasyarakatan. Manusia yang hidup dalam masyarakat tersebut sudah jelas di pengaruhi oleh berbagai paham dan tradisi yang ada di masyarakatnya. (Nata, 2001: 72).

Dengan masuknya Islam, Indonesia kembali mengalami proses akulturasi (proses bercampurnya dua (lebih) kebudayaan karena percampuran bangsabangsa dan saling mempengaruhi), yang melahirkan kebudayaan baru yaitu kebudayaan Islam Indonesia. Masuknya Islam tersebut tidak berarti kebudayaan Hindu dan Budha hilang.

Islam merupakan salah satu agama yang masuk dan berkembang di Indonesia. Hal ini tentu bukanlah sesuatu yang asing bagi Anda, karena di mass media mungkin Anda sudah sering mendengar atau membaca bahwa Indonesia adalah negara yang memiliki penganut agama Islam terbesar di dunia.

Menilik sejarah Islam Indonesia, kita dapat melihat bahwa Islam masuk dan menyebar ke Indonesia nyaris tanpa ada ketegangan dan konflik. Islam dengan mudah diterima oleh masyarakat sebagai sebuah agama yang membawa kedamaian, sekalipun kala itu masyarakat sudah mempunyai sistem kepercayaan tersendiri, baik berupa animisme maupun agama HinduBudha. (al-Humaidy, 2007: 278).

Di Indonesia terdapat berbagai macam ras, suku, bahasa, kebudayaan, agama dan kepercayaan. Semboyan "Bhineka Tunggal Ika" merupakan ungkapan yang tepat untuk menjelaskan realitas sekaligus harapan bangsa ini. Menurut Blaise Pascal seperti dikutip Harold Coward, Pluralisme yang tidak diintegrasikan dalam bentuk kesatuan adalah kekacauan, sedangkan kesatuan yang tidak menjaga pluralitas adalah tirani. (Coward, 1997: 123).

Meskipun Indonesia merupakan salah satu negara yang muslimnya mayoritas di dunia, namun paling sedikit mendapat pengaruh arabisasi, dibandingkan dengan negara-negara muslim besar lainnya. Selain itu, dalam proses Islamisasi di nusantara, penyebaran agama dan kebudayaan Islam tidak menghilangkan kebudayaan lokal dan tidak menggunakan kekuatan militer 
dalam upaya proses Islamisasi. Hal itu disebabkan karena proses Islamisasi dilakukan penetrasi secara damai melalui jalur perdagangan, kesenian, dan perkawinan dan pendidikan.

Sejalan dengan pemikiran tersebut diatas, penulis ingin menguraikan permasalahan yang akan dipokuskan pada bagaimana kajian tentang akulturasi Islam dan budaya lokal serta akulturasi timbal balik yang meliputi pengertian, latar belakang dan bagaimana hubungan ajaran agama yang universal dengan setting budaya lokal yang melingkupinya?

\section{PEMBAHASAN}

\section{Term Akulturasi}

Kata akulturasi berasal dari bahasa Inggris yaitu, acculturate yang artinya: menyesuaikan diri (kepada adat kebudayaan baru atau kebiasaan asing). (Shadily, 1976: 7). Sedangkan menurut kamus Besar Bahasa Indonesia "akulturasi" adalah percampuran dua kebudayaan atau lebih yang saling bertemu dan saling mempengaruhi atau proses masuknya pengaruh kebudayaan asing dalam suatu masyarakat, sebagian menyerap secara selektif sedikit atau banyak unsur kebudayaan asing itu.

Dari pengertian akulturasi ini, maka dalam konteks masuknya Islam ke Nusantara (Indonesia) dan dalam perkembangan selanjutnya telah terjadi interaksi budaya yang saling mempengaruhi. Namun dalam proses interaksi itu, pada dasar kebudayaan setempat yang tradisional masih tetap kuat, sehingga terdapat suatu bentuk perpaduan budaya asli (lokal) Indonesia dengan budaya Islam. Perpaduan inilah yang kemudian disebut akulturasi kebudayaan.

Akulturasi merupakan proses sosial yang timbul bila suatu kelompok manusia dengan suatu kebudayaan tertentu dihadapkan dengan unsurunsur dari suatu kebudayaan asing sedemikian rupa sehingga unsur-unsur kebudayaan asing lambat laun dapat diterima dan diolah ke dalam kebudayaan sendiri tanpa menyebabkan hilangnya kebudayaan itu sendiri.

Latar belakang sejarah sebagai bukti adanya akulturasi Islam dan budaya lokal. Sebelum Islam datang ke Indonesia, di Nusantara (Indonesia) telah berdiri kerajaan-kerjaan yang bercorak Hinduisme dan Budhisme. Seperti 
kerajaan Sriwijaya dan Majapahit. Akan tetapi setelah proses islamisasi dimulai sejak abad ke XIII, unsur agama Islam sangat memegang peranan penting dalam membangun jaringan komunikasi antara kerajaan-kerajaan pesisir dengan kerajaan-kerajaan pedalaman yang masih bercorak HinduBudha. Misalnya di daerah pesisir utara Jawa, kerajaan-kerajaan yang berdiri umumnya diperintah oleh pangeran-pangeran saudagar. Mereka takluk kepada raja Majapahit. Tetapi setelah raja-raja setempat memeluk agama Islam, maka mereka menggunakan Islam sebagai senjata politik dan ekonomi untuk membebaskan diri sepenuhnya dari kekuasaan Majapahit.

Setelah runtuhnya Majapahit $1520 \mathrm{M}$; di daerah pesisir proses Islamisasi berjalan sangat intensif hingga akhirnya berdirilah kerajaan-kerajaan Islam seperti, Demak, Banten dan Cirebon. Namun dalam segi pemahaman aqidah Islam, tidak serta merta mantap, dan melenyapkan alam pikiran filsafat lama, seperti Hindu dan Budha. Mereka memang mengucapkan kalimat Syahadat, akan tetapi kenang-kenangan dan praktik-praktik kepada kepercayaan kepada Bata Guru, Batara Wisnu, Dewata Sewwa'E, dan lain masih tetap hidup. Disinilah muncul kecenderungan sinkritisme. Dengan demikian, maka Islam yang berkembang di pedalaman Jawa berbeda dengan Islam yang berkembang di pesisir adalah Islam yang mobilitas sosialnya tinggi dan mengikuti perkembangan dunia Islam.

Setelah kerajaan Majapahit runtuh, maka muncul penggantinya di daerah pedalaman, muncullah kerajaan Mataram Islam tahun 1575 M. Karena masa peralihan yang lama antara kerajaan Islam pedalaman dan Islam pesisir, menyebabkan mereka saling berebut pengaruh yang menyebabkan terjadinya peperangan. Sultan Agung (1613 - 1645 M) dari kerajaan Mataram berusaha merebut kekuasaan kerajaan pesisir, sehingga unsur agama memegang peranan kembali, yakni di mata kerajaan-kerajaan pesisir kesultanan Mataram adalah kerajaan Islam yang sinkritisme. Di keraton kesultanan berkumpul segolongan pujangga yang mencampuradukkan antara Islam dengan Hindu, seperti terbukti pada Babad Tanah Jawa yang mengandung pencampuran Islam dengan Hinduisme.

Dalam kisah Babad Tanah Jawa di katakan bahwa, adapun raja-raja jawa berasal dari Nabi Adam yang mempunyai anak Sis, seterusnya mempunyai anak Nurcahya. Lalu Nurasa, kemudian Sang Hyang Wening, seterusnya sang Hyang 
Tunggal, dan akhirnya dijumpai Batara Guru yang gilirannya mempunyai Batara Wisnu sebagai salah seorang puteranya yang kemudian menjadi raja jawa dengan nama Pabru Set. Inilah sebuah contoh sinkritisme yang tidak disenangi oleh para alim ulama dan sultan-sultan pesisir. Sebagai bentuk kepeduliannya, maka para ulama di pesisir giat memasuki daerah pedalaman, melakukan gerakan dakwah di daerah kerajaan Mataram, menyerukan perlawanan rakyat terhadap Sultan Agung. Dari kisah Babad Tahan Jawa itu, maka kita dapat melihat bahwa telah menyebabkan terjadinya pertentangan antara kerajaan Islam di pesisir dengan sikap ortodoksnya , dengan kerajaan Islam pedalaman yang sinkritisme. Disinilah awal munculnya pertentangan antara Islam Sinkritisme dan ortodoks dalam arti telah terjadi pergumulan antara mempertahankan kemurnian akidah dengan pencampuran akidah yang dilakukan oleh kerajaan Islam di pedalaman(Hindu Budha kedalam Islam) demi mempertahankan pemburuan hegemoni kekuasaannya.

Oleh karena itu, dalam menyikapi akulturasi budaya analisis dari perspektif sejarah masuk dan berkembangnya Islam di Indonesia. Karena dalam proses Islamisasi di Indonesia tidak berjalan satu arah, tetapi banyak arah atau melalui berbagai macam pintu. Pintu-pintu itu, misalnya melalui kesenian, pewayangan, perkawinan, pendidikan, perdagangan, aliran kebatinan, mistisisme dan tasawuf.

Ini semua menyebabkan terjadinya kontak budaya, yang sulit dihindari unsur-unsur budaya lokal masuk dalam proses Islamisasi di Indonesia. Oleh karena itu kita sebagai muslim, harus punya sikap kritis dalam melihat konteks akulturasi Islam dan budaya lokal dalam menelaah sejarah Islam di Indonesia.

Kita harus punya pandangan, bahwa Islam itu bukanlah suatu sistem yang hanya membicarakan ke Tuhanan saja, tetapi yang tak kalah pentingnya adalah mengandung ajaran peradaban (tamaddun) yang komplit atau lengkap.

\section{Hubungan Ajaran Agama Yang Universal Dengan Setting Budaya Lokal Yang Melingkupinya.}

Universalisme Islam adalah salah satu karakteristik Islam yang agung. Islam sebagai agama yang besar berkarakteristikkan: (1) Rabbaniyyah, (2) Insaniyyah (humanistik), (3) Syumul (totalitas) yang mencakup unsur keabadian, universalisme dan menyentuh semua aspek manusia (ruh, akal, 
hati dan badan), (4) Wasathiyah (moderat dan seimbang), (5) Waqi'iyah (realitas), (6) Jelas dan gamblang, (7) Integrasi antara al-Tsabat wa al-Murunah (permanen dan elastis). (Qardhawi, 1993: 3).

Universalisme Islam yang dimaksud adalah bahwa risalah Islam ditujukan untuk semua umat, segenap ras dan bangsa serta untuk semua lapisan masyarakat. Ia bukan risalah untuk bangsa tertentu yang beranggapan bahwa dia-lah bangsa yang terpilih, dan karenanya semua manusia harus tunduk kepadanya.

Risalah Islam adalah hidayah Allah untuk segenap manusia dan rahmatNya untuk semua hamba-Nya. Maha Suci Allah yang telah menurunkan AlFurqon kepada hamba-Nya, agar dia menjadi pemberi peringatan kepada seluruh alam.

Ayat-ayat di atas yang nota bene Makkiyah, secara implisit membantah tuduhan sebagian orientalis yang menyatakan bahwa Muhammad Saw tidak memproklamirkan pengutusan dirinya untuk seluruh umat manusia pada awal kerisalahannya, akan tetapi setelah mendapat kemenangan atas bangsa Arab.

Universalisme Islam menampakkan diri dalam berbagai manifestasi penting, dan yang terbaik adalah dalam ajaran-ajarannya. Ajaran-ajaran Islam yang mencakup aspek akidah, syariah dan akhlak (yang sering kali disempitkan oleh sebagian masyarakat menjadi hanya kesusilaan dan sikap hidup), menampakkan perhatiannya yang sangat besar terhadap persoalan utama kemanusiaan.

Kosmopolitanisme Kebudayaan Islam. Selain merupakan pancaran makna Islam itu sendiri serta pandangan tentang kesatuan kenabian (wahdat al-nabawiyah; the unity of prophet) berdasarkan makna Islam itu, serta konsisten dengan semangat prinsip-prinsip itu semua, kosmopolitanisme budaya Islam juga mendapat pengesahan-pengesahan langsung dari kitab suci seperti suatu pengesahan berdasarkan konsep-konsep kesatuan kemanusiaan (wihdat al-insaniyah; the unity of humanity) yang merupakan kelanjutan konsep kemahaesaan Tuhan (wahdaniyat atau tauhid; the unity of god).

"Ummat manusia itu tak lain adalah ummat yang tunggal, tapi kemudian mereka berselisih (sesama mereka) jika seandainya tidak ada keputusan (kalimah) yang telah terdahulu dari Tuhanmu, maka tentulah segala perkara 
yang mereka perselisihkan itu akan diselesaikan (sekarang juga)”.

Para pengikut Nabi Muhammad diingatkan untuk selalu menyadari sepenuhnya kesatuan kemanusiaan itu dan berdasarkan kesadaran itu mereka membentuk pandangan budaya kosmopolit, yaitu sebuah pola budaya yang konsep-konsep dasarnya meliputi, dan diambil dari dari seluruh budaya ummat manusia. (Madjid, 1992: 442).

Refleksi dan manifestasi kosmopolitanisme Islam bisa dilacak dalam etalase sejarah kebudayaan Islam sejak jaman Rasulullah, baik dalam format non material seperti konsep-konsep pemikiran, maupun yang material seperti seni arsitektur bangunan dan sebagainya.

Pada masa awal Islam, Rasulullah Saw berkhutbah hanya sebuah pelepah kurma. Kemudian, tatkala kuantitas kaum muslimin mulai bertambah banyak, dipanggillah seorang tukang kayu Romawi. Ia membuatkan untuk Nabi sebuah mimbar dengan tiga tingkatan yang dipakai untuk khutbah Jumat dan munasabah-munasabah lainnya. Kemudian dalam perang Ahzab, Rasul menerima saran Salman al-Farisy untuk membuat parit (khandaq) di sekitar Madinah. Metode ini adalah salah satu metode pertahanan ala Persi. Rasul mengagumi dan melaksanakan saran itu. Beliau tidak mengatakan: "Ini metode Majusi, kita tidak memakainya!". Para sahabat juga meniru manajemen administrasi dan keuangan dari Persi, Romawi dan lainnya. Mereka tidak! keberatan dengan hal itu selama menciptakan kemashlahatan dan tidak bertentangan dengan nas. Sistem pajak jaman itu diadopsi dari Persi sedang sistem perkantoran (diwan) berasal dari Romawi.

Pengaruh filsafat Yunani dan budaya Yunani (hellenisme) pada umumnya dalam sejarah perkembangan pemikiran Islam sudah bukan merupakan hal baru lagi. Seperti halnya budaya Yunani, budaya Persia juga amat besar sahamnya dalam pengembangan budaya Islam. Jika dinasti Umawiyah di Damaskus menggunakan sistem administratif dan birokratif Byzantium dalam menjalankan pemerintahannya, dinasti Abbasiyah di Baghdad (dekat Tesiphon, ibu kota dinasti Persi Sasan) meminjam sistem Persia.

Islam, Bias Arabisme dan Akulturasi Timbal Balik dengan Budaya Lokal. Walaupun Islam sebagai agama bersifat universal yang menembus batasbatas bangsa, ras, klan dan peradaban, tak bisa dinapikan bahwa unsur Arab mempunyai beberapa keistimewaan dalam Islam. Ada hubungan kuat yang 
mengisyaratkan ketiadaan kontradiksi antara Islam sebagai agama dengan unsur Arab.

Menurut Dr.Imarah, hal ini bisa dilihat dari beberapa hal :

Pertama, Islam diturunkan kepada Muhammad bin Abdullah, seorang Arab. Juga, mukjizat terbesar agama ini, al-Quran, didatangkan dengan bahasa Arab yang jelas (al-Mubin), yang dengan ketinggian sastranya dapat mengungguli para sastrawan terkemuka Arab sepanjang sejarah. Sebagaimana memahami dan menguasai al-Quran sangat sulit dengan bahasa apapun selain Arab. Implikasinya, Islam menuntut pemeluknya jika ingin menyelami dan mendalami makna kandungan al-Quran, maka hendaknya mengarabkan diri.

Kedua, dalam menyiarkan dakwah Islam yang universal, bangsa Arab berada di garda depan, dengan pimpinan kearaban Nabi dan al-Quran, kebangkitan realita Arab dari segi "sebab turunnya wahyu" dengan peran sebagai buku catatan interpretatif terhadap al-Qur'an dan lokasi dimulainya dakwah di jazirah Arab sebagai "peleton pertama terdepan" di barisan tentara dakwahnya.

Ketiga, jika agama-agama terdahulu mempunyai karakteristik yang sesuai dengan konsep Islam lokal, kondisional dan temporal, pada saat Islam berkarakteristikkan universal dan mondial, maka posisi mereka sebagai "garda terdepan” agama Islam adalah menembus batas wilayah mereka. (Imarah, 1996: 11-12).

Walaupun begitu, menurut pengamatan Ibnu Khaldun, seorang sosiolog dan sejarawan muslim terkemuka, bahwa di antara hal aneh tapi nyata bahwa mayoritas ulama dan cendekiawan dalam agama Islam adalah 'ajam (non Arab), baik dalam ilmu-ilmu syariat maupun ilmu-ilmu akal. Kalau toh diantara mereka orang Arab secara nasab, tetapi mereka 'ajam dalam bahasa, lingkungan pendidikan dan gurunya. (Khaldun, 1989: 543).

Lebih lanjut, Ibnu Khaldun menjelaskan bahwa bersamaan dengan meluasnya daerah Islam, muncullah banyak masalah dan bid'ah, bahasa Arab sudah mulai terpolusikan, maka dibutuhkan kaidah-kaidah Nahwu. Ilmu-ilmu syariat menjadi keterampilan atau keahlian istinbath, deduktif, teoritisasi dan analogi. Ia membutuhkan ilmu-ilmu pendukung yang menjadi cara-cara dan metode-metode berupa pengetahuan undang-undang bahasa Arab dan aturan-aturan istinbath, qiyas yang diserap dari aqidah-aqidah 
keimanan berikut dalil-dalilnya, karena saat itu muncul bid'ah-bid'ah dan ilhad (atheisme). Maka jadilah ilmu-ilmu ini semua ilmu-ilmu keterampilan yang membutuhkan pengajaran. Hal ini masuk dalam golongan komoditi industri, dan sebagaimana telah dijelaskan, bahwa komoditi industri adalah peradaban orang kota sedangkan orang Arab adalah sangat jauh dari hal ini.

Ibnu Khaldun menyebutkan, intelektual-intelektual yang mempunyai kontribusi sangat besar dalam ilmu Nahwu seperti Imam Sibawaih, al-Farisi, dan al-Zujjaj. Mereka semua adalah 'ajam. Begitu juga intelektual-intelektual dalam bidang hadits, ushul fiqih, ilmu kalam dan tafsir. Benarlah sabda Rasulullah; "Jika saja ilmu digantungkan diatas langit, maka akan diraih oleh orang-orang dari Persia".

Kita lihat juga bahwa budaya Persia; budaya yang pernah jaya dan saat Islam masuk; ia sedang menyusut, adalah memiliki pengaruh yang demikian dalam, luas, dinamis dan kreatif terhadap perkembangan peradaban Islam. Lihat saja al-Ghazali, meskipun ia kebanyakan menulis dalam bahasa Arab sesuai konvesi besar kesarjanaan saat itu, ia juga menulis beberapa buku dalam bahasa Persi. Lebih dari itu, dalam menjabarkan berbagai ide dan argumennya, dalam menandaskan mutlaknya nilai keadilan ditegakkan oleh para penguasa, ia menyebut sebagai contoh pemimpin yang adil itu tidak hanya Nabi saw dan para khalifah bijaksana khususnya Umar bin Khattab, tetapi juga Annushirwan, seorang raja Persia dari dinasti Sasan.

Seperti di kemukakan diatas, Islam adalah agama yang berkarakteristikkan universal, dengan pandangan hidup (weltanchaung) mengenai persamaan, keadilan, takaful, kebebasan dan kehormatan serta memiliki konsep teosentrisme yang humanistik sebagai nilai inti (core value) dari seluruh ajaran Islam, dan karenanya menjadi tema peradaban Islam. (Kuntowijoyo, 1991: 229).

Pada saat yang sama, dalam menerjemahkan konsep-konsep langitnya ke bumi, Islam mempunyai karakter dinamis, elastis dan akomodatif dengan budaya lokal, selama tidak bertentangan dengan prinsip-prinsip Islam itu sendiri. Permasalahannya terletak pada tata cara dan teknis pelaksanaan. Inilah yang diistilahkan Gus Dur dengan "pribumisasi Islam".

Upaya rekonsiliasi memang wajar antara agama dan budaya di Indonesia dan telah dilakukan sejak lama serta bisa dilacak bukti-buktinya. Masjid 
Demak adalah contoh konkrit dari upaya rekonsiliasi atau akomodasi itu. Ranggon atau atap yang berlapis pada masa tersebut diambil dari konsep 'Meru' dari masa pra Islam (Hindu-Budha) yang terdiri dari sembilan susun. Sunan Kalijaga memotongnya menjadi tiga susun saja, hal ini melambangkan tiga tahap keberagamaan seorang muslim; iman, Islam dan ihsan. Pada mulanya, orang baru beriman saja kemudian ia melaksanakan Islam ketika telah menyadari pentingnya syariat. Barulah ia memasuki tingkat yang lebih tinggi lagi (ihsan) dengan jalan mendalami tasawuf, hakikat dan makrifat. (Wahid, 1989: 92).

Hal ini berbeda dengan Kristen yang membuat gereja dengan arsitektur asing, arsitektur Barat. Kasus ini memperlihatkan bahwa Islam lebih toleran terhadap budaya lokal. Budha masuk ke Indonesia dengan membawa stupa, demikian juga Hindu. Islam, sementara itu tidak memindahkan simbol-simbol budaya Islam Timur Tengah ke Indonesia. Hanya akhir-akhir ini saja bentuk kubah disesuaikan. Dengan fakta ini, terbukti bahwa Islam tidak anti budaya. Semua unsur budaya dapat disesuaikan dalam Islam. Pengaruh arsitektur India misalnya, sangat jelas terlihat dalam bangunan-bangunan mesjidnya, demikian juga pengaruh arsitektur khas mediterania. Budaya Islam memiliki begitu banyak varian.

Yang patut diamati pula, kebudayaan populer di Indonesia banyak sekali menyerap konsep-konsep dan simbol-simbol Islam, sehingga seringkali tampak bahwa Islam muncul sebagai sumber kebudayaan yang penting dalam kebudayaan populer di Indonesia.

Kosakata bahasa Jawa maupun Melayu banyak mengadopsi konsepkonsep Islam. Taruhlah, dengan mengabaikan istilah-istilah kata benda yang banyak sekali dipinjam dari bahasa Arab, bahasa Jawa dan Melayu juga menyerap kata-kata atau istilah-istilah yang berkenaan dengan ilmu pengetahuan. Istilah-istilah seperti wahyu, ilham atau wali misalnya, adalah istilah-istilah pinjaman untuk mencakup konsep-konsep baru yang sebelumnya tidak pernah dikenal dalam khazanah budaya populer.

Dalam hal penggunaan istilah-istilah yang diadopsi dari Islam, tentunya perlu membedakan mana yang "Arabi-sasi", mana yang "Islamisasi". Penggunaan dan sosialisasi terma-terma Islam sebagai manifestasi simbolik dari Islam tetap penting dan signifikan serta bukan seperti yang dikatakan 
Gus Dur, menyibukkan dengan masalah-masalah semu atau hanya bersifat pinggiran.

Begitu juga penggunaan term shalat sebagai ganti dari sembahyang (berasal dari kata 'nyembah sang Hyang') adalah proses Islamisasi bukannya Arabisasi. Makna substansial dari shalat mencakup dimensi individualkomunal dan dimensi peribumisasi nilai-nilai substansial ini ke alam nyata. Adalah naif juga mengganti salam Islam "Assalamu’alaikum” dengan "Selamat Pagi, Siang, Sore ataupun Malam”. Sebab esensi doa dan penghormatan yang terkandung dalam salam tidak terdapat dalam ucapan "Selamat Pagi" yang cenderung basa-basi, selain salam itu sendiri memang dianjurkan oleh Allah swt dan Rasul-Nya.

Gus Dur melihat Islam dan pluralisme itu dalam konteks manifestasi universalisme dan kosmopolitanisme dalam Islam. Menurutnya, ajaran yang dengan sempurna menampilkan universalisme adalah 5 (lima) jaminan dasar yang diberikan Islam kepada warga masyarakat, baik secara personal (individu) maupun sebagai kelompok (impersonal). Kelima jaminan dasar tersebut tersebar dalam literatur hukum agama (al-kutub al-fiqhiyah) lama, yang terdiri dari: 1) Keselamatan fisik warga masyarakat dari tindakan badani di luar ketentuan hukum; 2) Keselamatan keyakinan agama masing-masing tanpa ada paksaan untuk berpindah agama; 3) Keselamatan keluarga dan keterunan; 4) keselamatan harta benda dan milik pribadi di luar prosedur hukum; dan 5) keselamatan profesi. (Anwar, 1995: 233).

Secara keseluruhan, kelima jaminan dasar tersebut menampilkan universalitas pandangan hidup yang utuh dan bulat. Tetapi, kelima dasar itu hanya akan menyajikan kerangka teoritik atau mungkin hanya berdimensi moralistik belaka yang tidak berfungsi, jika tidak di dukung oleh kosmopolitanisme peradaban Islam, dimana ia muncul dalam sejumlah unsur dominan seperti hilangnya batasan etnis, kuatnya pluralitas budaya dan heterogenitas politik.

Dalam realitas kehidupan, watak kosmopolitanisme Islam sekarang itu sudah terlihat mulai hilang sehingga sebagian kaum muslim kini sudah menjadi "kelompok yang berpandangan sempit dan sangat ekslusif". Mereka akhirnya tidak mampu lagi mengambil bagian dalam peradaban manusia yang muncul dimasa pasca industri. Realitas problem tersebut membuat Gus 
Dur berharap agar umat Islam tidak terjebak dalam tawaran idealisme aspekaspek "Islam sebagai alternatf". Sebab tawaran seperti ini menurutnya hanya akan membuat idealisasi Islam jatuh, sama dengan usaha formalisasi Islam yang menghasilkan bangunan normatif Islam yang eksklusif dan picik.

Pandangan Gus Dur ini selaras dengan pandangan Nurcholish Madjid yang menginginkan agar universalisme dan kosmopolitanisme Islam itu tampil secara inklusif ditengah pluralitas budaya dan heterogenitas politik masyarakat. Hal ini karena pada dasarnya agama itu merupakan bagian dari manusia. Agama itu turun ke dunia bukan untuk menimbulkan peperangan, tatapi sebaliknya untuk menciptakan perdamaian, sebagai bimbingan bagi manusia bagaimana hidup yang baik, bergaul dengan orang sekitarnya dan berhubngan dengan alam semesta, termasuk hubungan dengan Tuhan.

Adanya kemungkinan akulturasi timbal balik antara Islam dengan budaya lokal diakui dalam suatu kaidah atau ketentuan dasar dalam ilmu ushul fiqh, bahwa "al-'adah muhakkamah," adat itu dihukumkan, atau lebih lengkapnya, "adat adalah syariat yang dihukumkan", artinya adat dan kebiasaan suatu masyarakat yaitu budaya lokalnya adalah sumber hukum dalam Islam. Karenanya, unsur-unsur budaya lokal yang dapat atau harus dijadikan sumber hukum adalah yang tidak bertentangan dengan prinsip-prinsip Islam.

Unsur-unsur yang bertentangan dengan prinsip Islam dengan sendirinya harus di hilangkan dan diganti. (As Syafi'i, t.th: 63). Inilah makna kehadiran Islam di suatu tempat atau negri. Dan ketika Islam datang ke tanah Jawa, Islam segera beradaptasi dengan apa yang ada. Akulturasi antara Islam dengan budaya setempat berlangsung secara damai. (Wahid, 1999: 66).

Dalam ilmu ushul fiqh, budaya lokal dalam bentuk kebudayaan itu di sebut 'urf. Karena 'urf suatu masyarakat sesuai dengan uraian di atas, mengandung unsur salah dan yang benar sekaligus, maka dengan sendirinya orang-orang muslim harus melihatnya secara kritis dan tidak dibenarkan sikap yang hanya membenarkan semata. Hal ini sesuai dengan berbagai prinsip Islam sendiri yang menentang tradisionalisme.

Jika demikian, jelaslah perjalanan sejarah rekonsiliasi antara Islam sebagai agama dan budaya lokal yang melingkupinya serta adanya landasan hukum legitimatif dari syara' berupa 'urf dan mashlahah. Maka untuk strategi pengembangan budaya Islam di Indonesia, kita perlu bervisi ke depan. Kenapa 
harus budaya? Karena budaya menyentuh seluruh aspek dan dimensi cara pandang, sikap hidup serta aktualisasinya dalam kehidupan manusia.

Selain itu, gerakan kultural lebih integratif dan massal sifatnya. Sehubungan dengan hal ini, kita patut mencontoh metodologi Sunan Kalijaga dalam menyebarkan Islam di Tanah Jawa. Sunan Kalijaga begitu melihat proses keruntuhan feodalisme Maja pahit dan digantikan oleh egalitarianisme Islam, ia mendorong percepatan proses transformasi itu, justeru dengan menggunakan unsur-unsur lokal guna menopang efektifitas segi teknis dan operasionalnya. Salah satu yang ia gunakan adalah wayang, juga gamelan yang dalam gabungannya dengan unsur-unsur upacara Islam populer adalah menghasilkan tradisi sekatenan di pusat-pusat kekuasaan Islam seperti Cirebon, Demak, Yogyakarta dan Surakarta.

\section{PENUTUP}

Islam adalah agama universal, yang tidak di khususkan pada umat dan bangsa tertentu sebagaimana agama-agama samawi sebelumnya. Misi utama Islam adalah rahmatan lil alamin, membawa kedamaian kepada seluruh alam. Dengan misi ini, Islam disebarkan ke seluruh dunia, termask Indonesia.

Penyebaran Islam ke berbagai wilayah di dunia ini, menyebabkan corak dan varian Islam memiliki kekhasan dan keunikan tersendiri dari pada Islam yang berkembang di Jazirah Arab. Demikian pun saat Islam menyebar ke Indonsia, Islam tidak terlepas dari budaya lokal yang sudah ada dalam masyarakat.

Islam yang yang berdialektika dengan budaya lokal tersebut pada akhirnya membentuk suatu varian Islam yang khas dan unik, seperti Islam Jawa, Islam Aceh, Islam Padang, Islam Sunda, Islam Sasak, Islam Bugis dan seterusnya.Varian Islam tersebut bukanlah Islam yang tercerabut dari akar kemurniannya, tapi Islam yang di dalamnya yang telah berakulturasi dengan budaya lokal. Jadi untuk strategi pengembangan budaya Islam di Indonesia, kita perlu bervisi ke depan. Kenapa harus budaya? Karena budaya menyentuh seluruh aspek dan dimensi cara pandang, sikap hidup serta aktualisasinya dalam kehidupan manusia. 


\section{DAFTAR PUSTAKA}

Al-Ahdali al-Yamani as Syafi'i. Abi Bakar al-Faraid al-Bahiyyah. Kudus: Menara Kudus.

Al-Humaidy, M. Ali. 2007. Tradisi Molodhan: Pemaknaan Kontekstual Ritual Agama Masyarakat pamkesan Madura, dalam jurnal ISTIQRO, Volume 06, nomor 01.

Coward, Harold. 1997. Setting the Research for Canadian Religius Pluralism, TTP: ARC.

Departemen Agama RI. 1992. Al-Quran dan terjemahannya; Juz 1-30 Edisi Revisi , Bandung: Gema Risalah.

Imarah, Muhammad. 1996. Al-Islam wa al-Arubah, al-Haiahal-Mashriyah al'Ammah li al-Kitab.

Jhon M. Echols dan Hasan Shadily. 1976. Kamus Inggris Indonesia, Jakarta: PT Gramedia Pustaka Utama.

Khaldun, Ibnu. 1989. Muqaddimah Ibnu Khaldun, Beirut, cet. VII.

Kuntowijoyo. 1991. Paridigma Islam, Mizan, cet. III.

M. Syafi'i Anwar. 1995. Pemikiran dan Aksi Islam Indonesia, Jakarta: Paramadina.

Madjid Nurkholis. 1992. Islam, Doktrin dan Peradaban, Jakarta, cet. II.

Nata, Abuddin. 2001. Peta Keragaman Pemikiran Islam di Indonesia, Jakarta: PT Raja Grafindo Persada.

Qardhawi, Yusuf. 1993. Al-khashaish al-'ammiyah al-Islam, Beirut cet. VIII.

Wahid, Abdurrahman. 1989. Pribumisasi Islam dalam Islam Indonesia, Menatap Masa Depan, P3M, Jakarta cet. I. . 1999. Membangun Demokrasi, Bandung: Remaja Rosdakarya. 